\title{
Fabrication of Micro Diamond Tools by Electroless Composite Plating and Micro Grinding
}

\author{
Heung-Kil PARK, Hiromichi ONIKURA, Osamu OHNISHI, Ahmad SHARIFUDDIN \\ Department of Intelligent Machinery and Systems, Kyushu University, Japan, Yoshizzang@hotmail.com
}

\begin{abstract}
:
This research deals with the development of micro grinding tools fabricated by electroless Ni-P composite plating with $5-10 \mu \mathrm{m}$ sized diamond grits and micro grinding. In this study, the fabrication of micro grinding tools for the grit amount was investigated and two kinds of tools were fabricated. The tools were used to micro grooving or drilling. Grooving with a groove depth of $100 \mu \mathrm{m}$ could be performed to about $600 \mathrm{~mm}$ on silicon. Also micro drilling was possible in silicon, quartz glass and metallic glass.
\end{abstract}

Keywords: Micro diamond tool, electroless composite plating, grinding, cemented carbide, micro grooving, micro drilling

\section{Introduction}

Micro machining technologies have become increasingly more important due to the increasing demand for the manufacture of precision parts and micro structured surfaces. LIGA process, micro electroforming and laser machining are known as the precision machining method. Although LIGA process is suitable for the mass production, it takes a lot of costs for synchrotron device and others. Also machining force is low in micro electroforming, but it takes a lot of time to fabricate the tool and its tool fabrication is limited to a simple shape. Laser machining does not come up to other processes for the viewpoint of quality.

On the other hand, the mechanical process plays a significant role for the generation of micro structured surface and precision parts. Because the mechanical process is considered as the most economical method, the demand for the development of micro tools and components by this process is continuously increasing. Among the mechanical processes, micro grinding has a prominent advantage with respect to the applicability to any materials, e.g., silicon, glass, carbide, ceramic, metal, etc. But the electroplated grinding tool has been the main stream in the tool fabrication by the wet method.

Electroless plating has a high surface hardness and the uniformity of plating film. We had investigated the fabrication possibility of EN (electroless nickel) plated grinding tool. And we fabricated the micro grinding tools by electroless composite plating with $5-10 \mu \mathrm{m}$ sized diamond grits and then applied the tools to micro machining. Tool life was investigated through the micro grooving of a $100 \mu \mathrm{m}$ groove depth and micro drilling was performed in silicon, quartz glass and metallic glass.

\section{Experiment}

\subsection{Electroless plating and composite plating}

EN plating is the chemical reduction plating that depends on the catalytic reduction process of nickel ions in an aqueous solution (containing a chemical reducing agent) and the subsequent deposition of nickel metal without the use of electrical energy.

In EN plating process, the driving force for the reduction of nickel metal ions and their deposition is supplied by a chemical reducing agent in solution. This driving potential is essentially constant at all points of the surface of a substrate, provided the stir of solution is sufficient to ensure a uniform concentration of metal ions and reducing agents. Electroless deposits are therefore very uniform in thickness all over the part's shape and size [1].

The electroless composite plating film is deposited by collision and settling of particles on the substrate surface, and these particles are fixed by the subsequent envelopment of the matrix material as it is deposited. And the mechanism of electroless composite plating is easily explained as follows;

(1) Dispersed particles are moved to the interface of substrate and solution

(2) Particles are adhered to the surface of the plated film on substrate

(3) Particles are fixed by the metal that is plated subsequently on substrate

(4) The fixed particles are embedded

\section{2 Electroless $\mathrm{Ni}-\mathrm{P}$ plating solution}

The EN plating solution is needed to fabricate micro grinding tool promptly and we developed EN plating solution. The chemical composition is shown in Table 1 and a small amount of thiourea has been added to the solution as a stabilizer. Nickel sulfate is used as a metal salt which includes metal (ion) that is plated on the substrate and sodium hypophosphite works as a reducing agent that gives electron to extract metallic ion as metal. Sodium acetate is used as a supplementary component to prevent the spontaneous decomposition of EN solution and keep solution $\mathrm{pH}$ from changing [2] [3] [4].

Table 1: Chemical composition of EN solution

\begin{tabular}{|c|c|}
\hline Bath composition & Concentration \\
\hline Nickel sulfate & $30 \mathrm{~g} / \mathrm{L}$ \\
\hline Sodium hypophosphite & $20 \mathrm{~g} / \mathrm{L}$ \\
\hline Sodium acetate & $20 \mathrm{~g} / \mathrm{L}$ \\
\hline
\end{tabular}

\subsection{Experimental procedure}

In the experiment the tool fabrication process consists of pretreatment of substrate to clean it, EN composite plating 
with diamond grits and embedding of them through the plated film.

At first, the cleaning of substrate was conducted by acetone with ultrasonic vibration, and then electrolytic degreasing, acid pickling, Ni strike plating, EN composite plating and embedding were carried out in order. EN composite plating was performed with a temperature of $80^{\circ} \mathrm{C}$. $5-10 \mu \mathrm{m}$ sized diamond grits were plated on the cylindrical and round point substrates of cemented carbide with diameters of $100 \mu \mathrm{m}$ and $300 \mu \mathrm{m}$ and tip lengths of $0.5 \mathrm{~mm}$ and $1.5 \mathrm{~mm}$, respectively. Figure 1 shows the geometry of the substrate.

Tool substrate has to be quickly immersed into EN plating solution when pretreatment is over, and then EN composite plating can occur subsequently. In the tool fabrication process, a substrate was rotated to plate diamond grits uniformly on its surface with the rotation spindle shown in Figure 2. With rotating substrate, EN plating solution was stirred from the bottom of container by a stirrer and it makes diamond grits to be distributed in the solution uniformly.

\section{Tool fabrication}

When the tool was fabricated, experimental factors that were chiefly considered in this research were the amount of grit addition, solution stirring and substrate rotation. And the effects of each factor are described as follows.

\subsection{Effect of stirring solution}

At first, micro tool was fabricated with the substrate of a diameter of $100 \mu \mathrm{m}$. And one of the important factors considered when the tool was fabricated was the stir of solution. If solution is stirred too slowly, the tool can not be fabricated due to precipitating in the solution of diamond grits. Oppositely, if solution is stirred rapidly, grits collide strongly with the substrate surface and then it can not be adhered on the surface. Thus in this research the tool could be steadily fabricated by setting the stir speed of solution at $50-60 \mathrm{~min}^{-1}$.

\subsection{Effect of substrate rotation}

When the rotational speed of substrate was more than $3 \mathrm{~min}^{-1}$, diamond grits came to be hardly fixed to the point part. It can be considered that diamond grits fall from the substrate surface because they are affected by both the rotational speed of substrate and the stir speed of solution. So when the micro grinding tool is fabricated with $5-10 \mu \mathrm{m}$ sized diamond grits, the rotational speed of substrate should be slow down to $1 \mathrm{~min}^{-1}$.

\subsection{Effect of grit amount}

Diamond grits were added in the solution, and the tool was fabricated while substrate being slowly rotated with a speed of $1 \mathrm{~min}^{-1}$. Figures 3 and 4 show the micro tools fabricated with grit amounts of $5 \mathrm{~g} / \mathrm{L}$ and $10 \mathrm{~g} / \mathrm{L}$, respectively. In result, grit density on the micro tool surface increased to more than 30 percent through doubling the amount of diamond grits.

\subsection{Tool fabrication applied EN plating uniformity}

The substrate shape can be kept because EN plating film is deposited uniformly on its surface. So another work such as dressing is not needed even if the composite

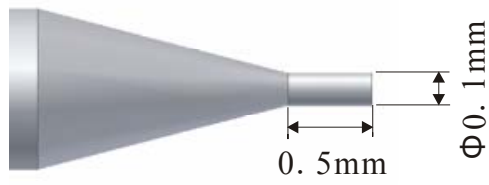

(a) $100 \mu \mathrm{m}$ diameter substrate

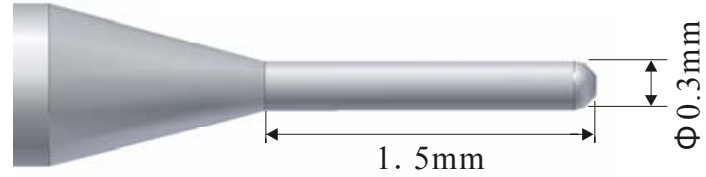

(b) $300 \mu \mathrm{m}$ diameter substrate

Figure 1: Geometry of cemented carbide substrate

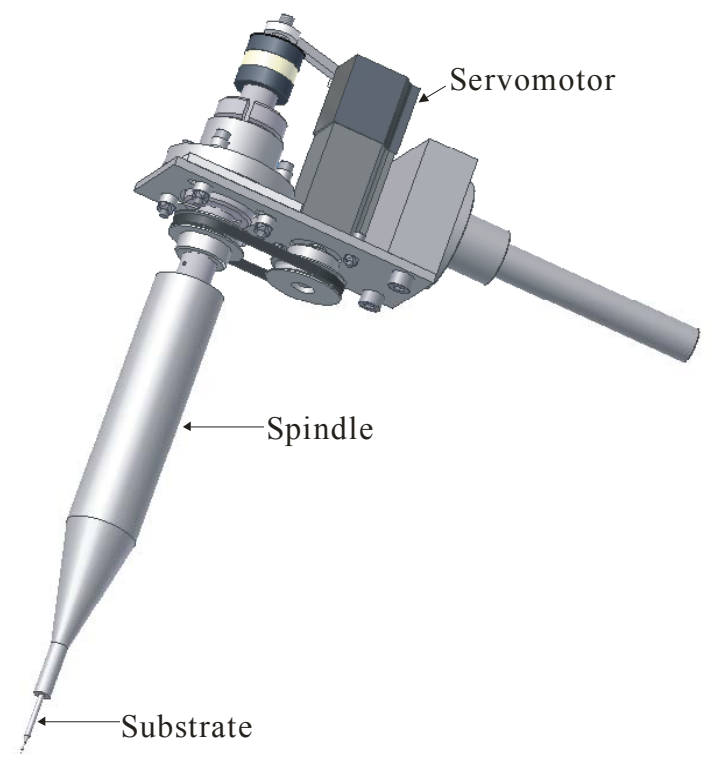

Figure 2: Substrate rotation spindle

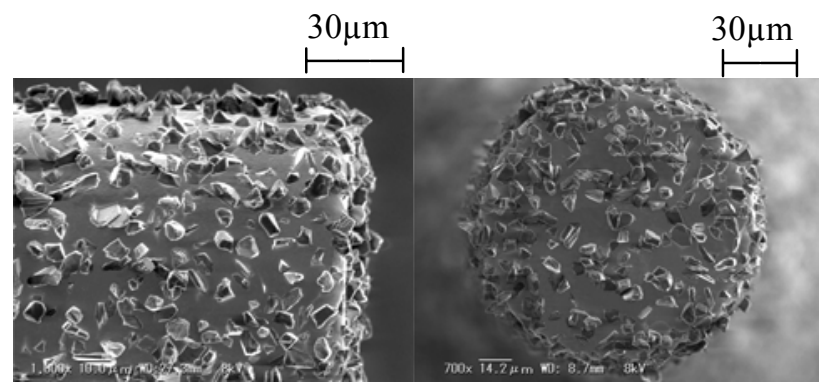

(a) Side view

(b) Top view

Figure 3: Tool fabricated with a girt amount of $5 \mathrm{~g} / \mathrm{L}$

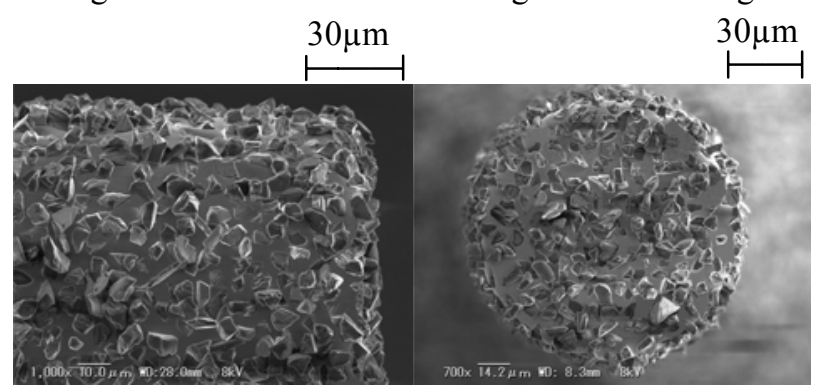

(a) Side view

(b) Top view

Figure 4: Tool fabricated with a grit amount of $10 \mathrm{~g} / \mathrm{L}$ 
plating is performed. Figure 5 shows the micro tools fabricated with substrates of Figure 1. The stir speed of solution, substrate rotation and grit amount are $50-60 \mathrm{~min}^{-1}$, $1 \mathrm{~min}^{-1}$ and $10 \mathrm{~g} / \mathrm{L}$, respectively. As shown in Figures 5 (a) and (b), the tool point keeps the shape of its substrate.

\section{Micro machining}

After the micro grinding tool was fabricated, tool life was investigated through micro grooving on brittle materials like single crystalline silicon and quartz glass with the tool of Figure 3. Here, for micro grooving, tool life is defined as the total machining length to tool breakage. Micro drilling was carried out with the micro tools of Figures 3 and 4 to investigate which tool is suitable for drilling. The tool of Figure 4 was selected for micro drilling because holes could be drilled much more.

\subsection{Micro grooving}

The upper surface and each side surface of workpiece are ground with a diamond wheel in order to get the same plane height. After the tool location is set in origin based on the workpiece upper surface, the main spindle moves to $100 \mu \mathrm{m}$ lower in the direction of $\mathrm{Z}$ and then micro tool grinds workpiece to $5 \mathrm{~mm}$ in the direction of $\mathrm{X}$ with the determined feed speed and the grinding process is repeated to tool breakage. Micro grooving was performed with a grinding speed of $11.78 \mathrm{~m} / \mathrm{min}$ and a feed of $80 \mathrm{~nm} / \mathrm{rev}$ using the cylindrical tool.

Two kinds of brittle materials, silicon and quartz glass, were used as workpiece. A transparent material represente$\mathrm{d}$ by quartz glass is being used widely as the basic material of light-electronics field. The development of high-quality and cheap precision machining technology is expected by advancement of photonic technology, and so we have tried to machine quartz glass through micro grinding according to such industrial needs.

The micro grooving result is shown in Figure 6. From the result, the tool life became three times longer in single crystalline silicon than in quartz glass. It seems that quartz glass can be destroyed more easily than silicon and the cutting chip is adhered to the tool surface firmly because the material properties of compression strength and fracture toughness, etc. fall compared with that of single crystalline silicon. And then it is considered that because micro grooving was performed with the cutting chip of quartz glass adhered to the tool surface, the exhaust of the chip and the wear-out of the tool became awful, and at the end the tool life fell.

Figures 7 and 8 show micro grooves ground on silicon and quartz glass, respectively. And the grooving depth was set at $100 \mu \mathrm{m}$ and each depth looks like different because the setting angles of SEM were a little different. As shown in Figures 7 (a) and 8 (a), the mark of tool point plane remains in the bottom of the first groove. It is considered that diamond particles clung lightly on the tool surface come off at the beginning of grinding, and then such a mark remains on the bottom of the first one.

\subsection{Micro drilling}

Micro drilling of hard and brittle materials used a cutting tool was performed by several researchers [5][6].
When hardness and brittle characteristics are considered, the drilling process using a grinding tool seems to be performed easily in such materials. In this study, micro drilling used a grinding tool was performed with a step feed of $20 \mu \mathrm{m}$ and at a penetration of $1.67 \mu \mathrm{m} / \mathrm{s}$.

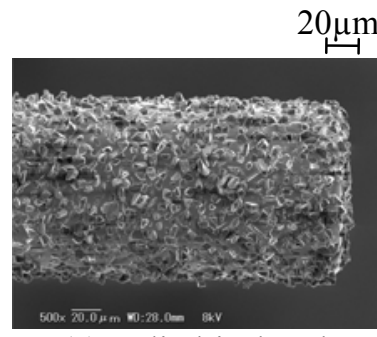

(a) Cylindrical tool

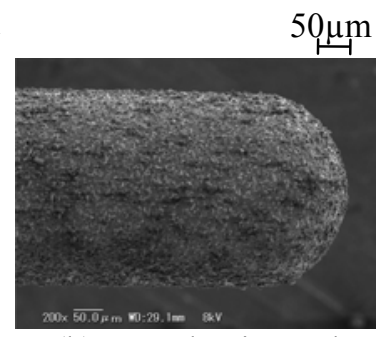

(b) Round point tool
Figure 5: Tool geometry after EN composite plating

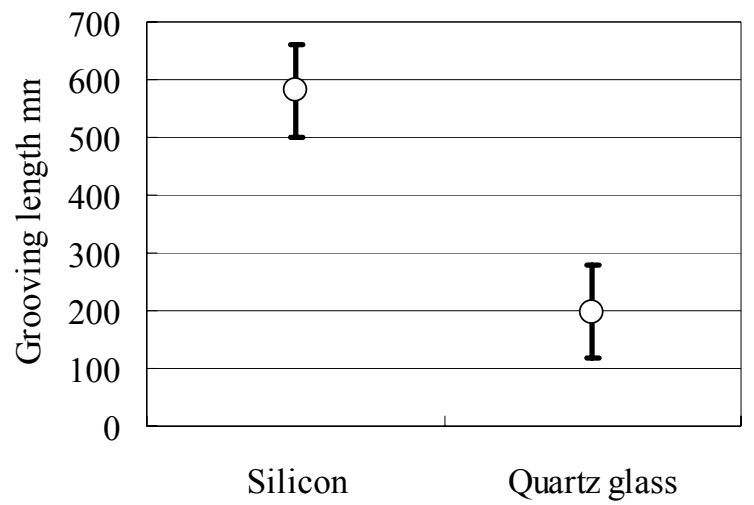

Figure 6: Tool life of micro grooving

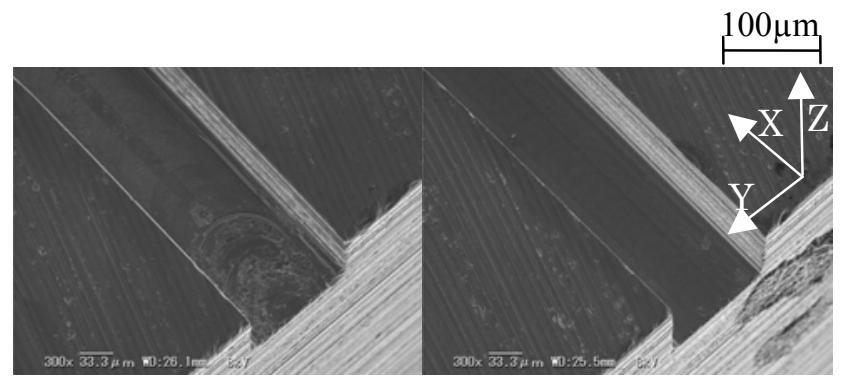

(a) $5 \mathrm{~mm}$

(b) $100 \mathrm{~mm}$

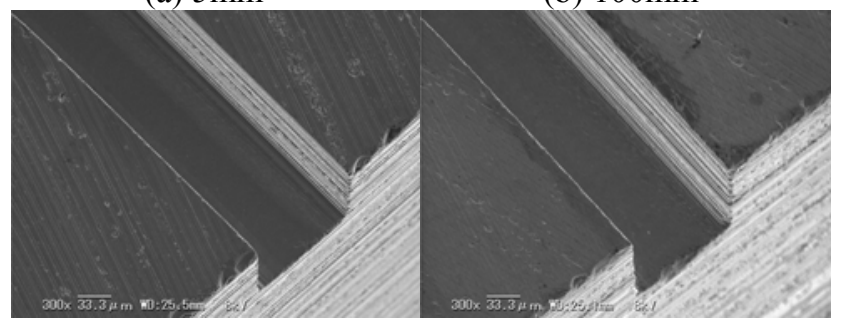

(c) $150 \mathrm{~mm}$

(d) $300 \mathrm{~mm}$

Figure 7: Micro groove on silicon

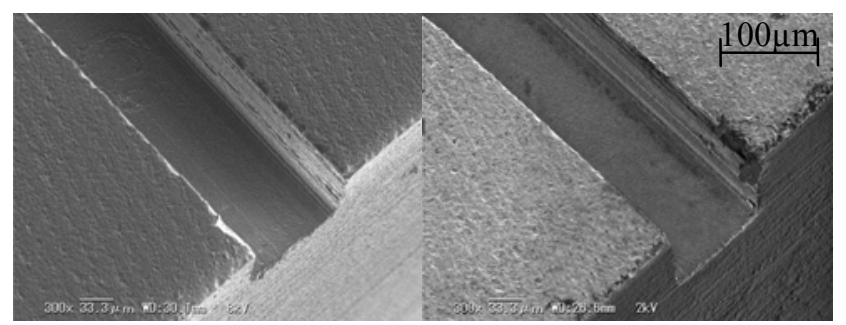

(a) $5 \mathrm{~mm}$

(d) $250 \mathrm{~mm}$

Figure 8: Micro groove on quartz glass 


\subsubsection{Drilling in single-crystalline silicon}

Micro drilling with a depth of $200 \mu \mathrm{m}$ was performed in silicon with the tool of Figure 4. Figure 9 shows the drilled holes. To about the 30th hole, just a small crack was observed around the rim of hole and the shape of hole was clear. On the other hand, from more than the 30th hole fracture and crack became large suddenly. And it can be considered that the sudden fracture and crack mean the end of tool life for micro drilling.

\subsubsection{Drilling in quartz glass}

Micro drilling in quartz glass using the tool of Figure 4 could be performed to more than 40 holes without significant fracture and crack around the rim of hole.

Dimple-type hole was machined on quartz glass with the tool of Figure 5 (b). Figure 10 shows the dimple-type holes and the hole pitch is $350 \mu \mathrm{m}$. The lines inside the holes stand out and it seems that it is the marks left by large diamond grit. This drilling was performed to show that in this micro grinding process the various shapes of holes, e.g., dimple-type, conic-type, etc. could be simply drilled by changing the substrate shape.

\subsubsection{Drilling in metallic glass}

Drilling is one of the important machining processes to produce BMG (bulk metallic glass) parts with complicated shape and high dimensioned accuracy. Several researchers have investigated the drilling process of Zr-based BMG and the researches were about the drilling process using a cutting tool [7] [8]. And we thought that micro drilling using a diamond grinding tool could be performed in the material. We have examined drilling with a micro grinding tool and micro drilling in metallic glass was possible to several holes. In this study, ultrasonic vibration cutting by workpiece vibration was carried out. And the metallic glass was vibrated vertically at a frequency of $60 \mathrm{kHz}$. The amplitude was about $1.5 \mu \mathrm{m}$ in all experiments. Figure 11 shows micro blind holes with a diameter of about $330 \mu \mathrm{m}$ and a hole depth of $600 \mu \mathrm{m}$.

\section{Conclusions}

Two kinds of micro grinding tools were fabricated by the difference of the grit amount, $5 \mathrm{~g} / \mathrm{L}$ and $10 \mathrm{~g} / \mathrm{L}$, using $5-10 \mu \mathrm{m}$ sized diamond grits.

The tool fabricated with a grit amount of $5 \mathrm{~g} / \mathrm{L}$ was used for micro grooving and the tool life in single crystalline silicon has been three times longer than that in quartz glass. In the bottom of each first groove, the grinding mark of tool point plane remained. It seems because diamond particles clung lightly on the tool surface came off on the bottom in the first groove at the beginning of grinding.

With using the tool fabricated with a grit amount of $10 \mathrm{~g} / \mathrm{L}$, micro drilling was performed in both silicon and quartz glass and more than 30 holes were drilled in both materials. It is considered that the micro grinding tool fabricated by EN composite plating can be also applied to drilling process.

Dimple-type hole was machined on quartz glass and it means that the various shapes of holes can be simply drilled by changing the substrate shape.
Finally, Zr-based metallic glass was drilled using a micro grinding tool and blind holes with a diameter of about $330 \mu \mathrm{m}$ and a depth of $600 \mu \mathrm{m}$ could be drilled.

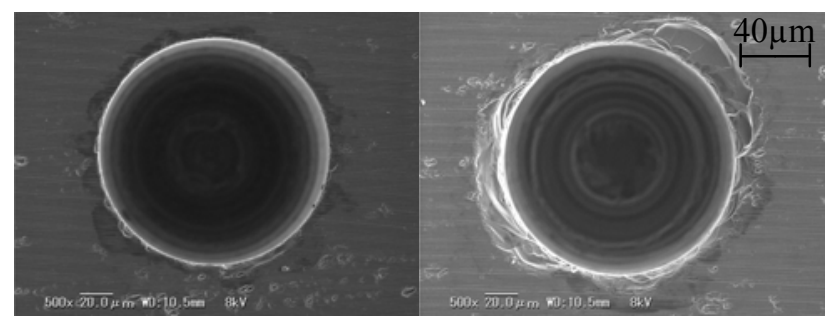

(a) 30th hole

(b) 32nd hole

Figure 9: Micro hole machined on silicon

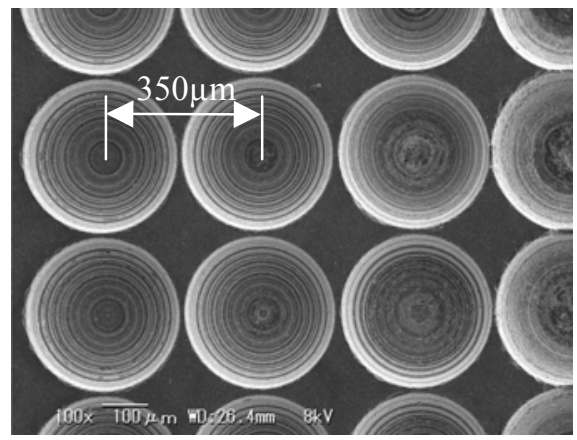

Figure 10: Dimple on quartz glass

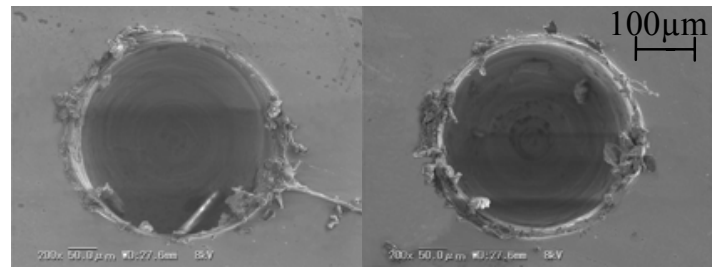

(a) 1st hole

(b) 4th hole

Figure 11: Hole drilled on metallic glass

\section{References}

[1] Libo Li, Maozhong An and Gaohui Wu, 2006, Surface and Coatings Technology, Volume 200, pp.5102-5112

[2] W.J. Cheong, Ben L. Luan and David W. Shoesmith, 2004, Applied Surface Science, Volume 229, pp.282-300

[3] J.T. Winowlin Jappes, B. Ramamoorthy and P. Kesavan Nair, 2005, Journal of Materials Processing Technology, Volume 169, pp.308-313

[4] I. Baskaran, T.S.N. Sankara Narayanan and A. Stephen , 2006, Materials Chemistry and Physics, Volume 99, pp.117-126

[5] K. Egashira, K. Mizutani, 2002, Precision Engineering, Volume 26, pp263-268

[6] K.Egashira, K.Mizutani, 2002, Annals of the CIRP, Volume 51, pp.339-342

[7] M. Bakkal, A.J. Shih, S.B. McSpadden, C.T. Liu and Ronald O. Scattergood, 2005, International Journal of Machine Tools and Manufacture, Volume 45, pp.741-752

[8] M. Bakkal, A.J. Shih, S.B. McSpadden and Ronald O. Scattergood, 2005, International Journal of Machine Tools and Manufacture, Volume 45, pp863-872 